\title{
Comparison between Retinal Ophthalmoscopy Vs Fundus Photography with ETDRS Field for Clinical Screening of Diabetic Retinopahty
}

\author{
Prerana Patil ${ }^{1}$, Niharika Krishna Shetty ${ }^{2}$ \\ ${ }^{1,2}$ Department of Ophthalmology, Sri Siddhartha Medical College Hospital, \\ Sri Siddhartha Academy of Higher Education University, Tumkur, Karnataka, India.
}

\section{ABSTRACT}

\section{BACKGROUND}

Screening of Diabetic retinopathy is essential for detection of diabetic retinopathy and its management. Diabetic retinopathy is a common and preventable cause of blindness in adults. Laser pan-retinal photocoagulation has been proven to have established efficacy in treating diabetic visual loss. Since India has a wide geographical area and there is a lack of trained ophthalmologists in peripheral India, there is an immense need for telemedicine in diabetic retinopathy screening. This study was done to evaluate the comparability of non-stereoscopic fundus photography with conventional fundoscopy for detection of diabetic maculopathy.

\section{METHODS}

All patients with diabetic retinopathy and mixed retinopathy presenting to Ophthalmology OPD at Sri Siddhartha Medical College between June 2020 and June 2021, were included in the study. The patients were evaluated for visual acuity on Snellen Visual Acuity Chart, Anterior Segment evaluation on a slit-lamp examination. Fundus was evaluated with 90 Diopter Volk lens with Slit Lamp biomicroscopy, Direct Ophthalmoscopy with Welch Allyn ophthalmoscope with medium size aperture, and the peripheral fundus was seen by an Indirect Ophthalmoscope with 20 Diopter lens Volk lens. ETDRS 7 Field Picture on Carl Zeiss Meditec AG VISUCAM SN model AA107 was taken. The observations were subjected to the statistical analysis of Cohen's Kappa and the percentile description.

\section{RESULTS}

The commonest retinopathy was moderate non-proliferative diabetic retinopathy (NPDR), seen in $41.667 \%$. The commonest maculopathy found was the absence of maculopathy seen in $78.3 \%$ of cases. There was perfect agreement (Kappa k-1.00) in the evaluation of background retinopathy on Conventional Fundoscopy and Fundus imaging, P-value $<0.001$. There was moderate agreement (Kappa k-0.5) in the evaluation of maculopathy on Conventional Fundoscopy and Fundus imaging, Pvalue $<0.001$, only for CSME and No maculopathy. However diffuse macular oedema and Ischemic Maculopathy were missed on Fundus Photography.

\section{CONCLUSIONS}

Non-Stereoscopic Fundus Photography is a good telemedicine tool for diabetic retinopathy screening, but there is under-diagnosis of it, though it can detect diabetic maculopathy. As a diagnosis" Absence of maculopathy" is inconclusive until and unless screened by Conventional Ophthalmoscopy.

\section{KEY WORDS}

Diabetic Retinopathy, Maculopathy, Clinically Significant Macular Oedema, NonStereoscopic Fundus Imaging, Ophthalmoscopy.
Corresponding Author: Dr. Niharika Krishna Shetty, C-1403, Wing 1, Vaishnavi ARS Gardenia, Subrotho Mukherjee Road, Jallahalli West, Dasarahalli, Bangalore-560057,

Karnataka, India.

E-mail: niharika.shetty30@gmail.com

DOI: $10.14260 /$ jemds/2022/27

How to Cite This Article:

Patil P, Shetty NK. Comparison between retinal ophthalmoscopy vs fundus photography with ETDRS field for clinical screening of diabetic retinopathy. J Evolution Med Dent Sci 2022;11(01):141146, DOI: 10.14260/jemds/2022/27

Submission 10-12-2021,

Peer Review 14-01-2022,

Acceptance 20-01-2022,

Published 28-01-2022.

Copyright (C) 2022 Prerana Patil et al. This is an open access article distributed under Creative Commons Attribution License [Attribution 4.0 International (CC BY 4.0)] 


\section{BACKGROUND}

Diabetic retinopathy is a common and preventable cause of blindness in adults. ${ }^{1,2}$ Screening for diabetic retinopathy is an important tool for managing diabetic retinopathy related blindness since laser pan-retinal photocoagulation has been proven to have established efficacy in treating diabetic visual loss. ${ }^{3}$

The various clinical methods of evaluation of diabetic retinopathy include direct and indirect ophthalmoscopy and various imaging techniques. The various imaging techniques include fundus photography, fluorescein angiography, B-scan ultrasonography, and optical coherence tomography. ${ }^{4}$

The clinical evaluation of the retina on ophthalmoscopy requires an ophthalmologist to do it, whereas the digital imaging can be done by paramedical or technical staff, and can also be done at a remote setting. Tele-reporting of these fundus images can be done by an ophthalmologist and timely referral of severe vision-threatening retinopathy can be done.

Telemedicine is sharing of medical data by electronic telecommunications technology that allows a patient's medical problems to be evaluated and monitored by a remotely located ophthalmologist. Diabetic retinopathy is a disease that can efficiently utilize telemedicine for reducing its visual burden. Many telescreening methods are used in diabetic retinopathy like stereoscopic imaging, non-mydriatic camera and mobile phone-based fundus camera that show comparable sensitivity and specificity in diagnosing diabetic retinopathy. $3,5,6$

India has a wide geographical area and there is a lack of trained ophthalmologists in peripheral India. Studies have highlighted the lack of connectivity and trained optometrists in such areas. In some centres, these paramedic staffs attend to a population of $50,000 .^{7}$

In this study, we have compared the clinical evaluation of the retina using direct and indirect ophthalmoscopy with standard non-stereoscopic fundus colour photography.

The other methods include wide-field fundus photography and stereographic photography.

The Standard Colour Photograph images the central (degree 30 or 45 ) of the macula and the optic disc. The clinical features of the macula can be used to detect maculopathy, however since it is a two-dimensional image, the macular thickness in the spongiform type of maculopathy and CSME might not be correctly commented on.

Further, a 7 field ETDRS view of the fundus is a montage view and can evaluate approximately 75 degrees of the visual field. This image helps to classify the peripheral diabetic retinopathy into proliferative and non-proliferative diabetic retinopathy.

The International Clinical disease severity scale that was used for this study was based on the Wisconsin Epidemiologic Study of Diabetic Retinopathy (WESDR) and the ETDRS. Five stages are recognized as per the scale, namely no retinopathy, mild, moderate, severe, and very severe retinopathy. $8,9,10$

The maculopathy in diabetes is graded as clinically significant macular oedema, diffuse and focal maculopathy. ${ }^{10,11}$
Now further advancement with, many computer-aided diagnostic software systems for eye diseases using digital fundus images have been developed. Such a system can differentiate between affected eyes compared to normal eyes. This will significantly reduce the workload for the ophthalmologists. ${ }^{12,13}$

\section{METHODS}

In this cross-sectional study, all patients attending ophthalmology OPD and admitted patients in wards with suspicion of diabetes mellitus and diagnosed cases in Sri Siddhartha medical college and hospital, Tumkur from June 2020 to June 2021 were included. Purposive sampling was the method used.

\section{Inclusion Criteria}

1. Patients with a known history of diabetes.

2. Patients with high blood glucose but not diagnosed.

3. Patients above the age of 18 years.

\section{Exclusion Criteria}

1. Patients with media opacity.

2. Patients with occlusive/vascular retinal disease.

3. Patients who have undergone vitro-retinal surgeries.

\section{Method of Collection of Data}

All patients with diabetic retinopathy and mixed retinopathy presenting to Ophthalmology OPD were included in the study. The patients were evaluated for visual acuity on Snellen Visual Acuity Chart, Anterior Segment evaluation on a Slit lamp examination. Fundus was evaluated with 90 Diopter Volk lens with Slit Lamp biomicroscopy, Direct Ophthalmoscopy with Welch Allyn ophthalmoscope with medium size aperture, and the peripheral Fundus was seen by an Indirect Ophthalmoscope with 20 Diopter lens Volk lens. The type of retinopathy and maculopathy was graded according to the International Disease Severity Classification ${ }^{8}$ and ETDRS classification. The retinal picture was then captured with, Carl Zeiss Meditec AG VISUCAM SN model AA107. The fields evaluated were central field for maculopathy and ETDRS 7 field picture montage program. Both were inbuilt in the camera. The diagnosis on the camera was put by the same ophthalmologist who evaluated the fundus clinically and then both were compared. The ethical approval was taken from the institutional ethical committee, Ref No: SSMC/Med/IEC-1/March-2020 dated 13/03/2020 The ethical concerns of the tenets of Helsinki were followed during the study.

\section{Statistical Analysis}

The observations were subjected to the statistical analysis of Cohen's $\mathrm{Kappa}^{28}$ and the percentile description. The conclusions were drawn from the table. 


\section{RESULTS}

\begin{tabular}{|ccc|}
\hline \multicolumn{3}{|c|}{$\begin{array}{c}\text { Frequencies for Age in Years } \\
\text { Age in Years }\end{array}$} \\
Frequency & Percent \\
$40-45$ & 6 & 10.000 \\
$46-50$ & 9 & 15.000 \\
$51-55$ & 9 & 15.000 \\
$56-60$ & 17 & 28.333 \\
$61-65$ & 12 & 20.000 \\
$>66$ & 7 & 11.667 \\
\hline Table 1. Age Distribution in Diabetic Retinopathy \\
\hline
\end{tabular}

In our study, we found a maximum of 29 (48\%) patients in the 56 to 65 years of age group.

\begin{tabular}{|ccc|}
\hline \multicolumn{3}{|c|}{ Frequencies for Gender } \\
Gender & Frequency & Percent \\
Male & 35 & 58.333 \\
Female & 25 & 41.667 \\
\hline Table 2. Gender Distribution in Diabetic Retinopathy \\
\hline
\end{tabular}

In our study, we had a male preponderance with 35 (58.33\%) patients belonging to the group.

\begin{tabular}{|c|cc|}
\hline $\begin{array}{c}\text { Frequencies for ETDRS Background Retinopathy Conventional } \\
\text { Fundoscopy }\end{array}$ & \\
$\begin{array}{c}\text { ETDRS Background Retinopathy } \\
\text { Conventional Fundoscopy }\end{array}$ & Frequency & Percent \\
Mild NPDR & 14 & 23.333 \\
Moderate NPDR & 25 & 41.667 \\
Severe NPDR & 11 & 18.333 \\
PDR & 10 & 16.667 \\
\hline Table 3. Frequency Distribution of Background Diabetic Retinopathy \\
on Conventional Fundoscopy \\
\hline
\end{tabular}

In our study, it was found that the commonest type of retinopathy in conventional fundoscopy was moderate NPDR 25 (41.667 \%) based on ETDRS classification.

\begin{tabular}{|c|c|c|}
\hline \multicolumn{3}{|c|}{ Frequencies for ETDRS Background Retinopathy Fundus Imaging } \\
\hline $\begin{array}{l}\text { ETDRS Background Retinopathy Fundus } \\
\text { Imaging }\end{array}$ & Frequency & Percent \\
\hline Mild NPDR & 14 & 23.333 \\
\hline Moderate NPDR & 25 & 41.667 \\
\hline Severe NPDR & 11 & 18.333 \\
\hline PDR & 10 & 16.667 \\
\hline $\begin{array}{r}\text { istribution of Back } \\
\text { on Fundus Ima }\end{array}$ & & \\
\hline
\end{tabular}

The commonest retinopathy on fundus imaging was moderate, seen in 25 (41.66 \%) cases.

\begin{tabular}{|ccc|}
\hline $\begin{array}{c}\text { ETDRS Maculopathy Conventional } \\
\text { Ophthalmoscopy }\end{array}$ & Frequency & Percent \\
No Maculopathy & 47 & 78.333 \\
CSME & 5 & 8.333 \\
Ischemic maculopathy & 2 & 3.333 \\
Diffuse macular oedema & 6 & 10.000 \\
\hline \multicolumn{2}{|c|}{ Cable 5. Frequency Distribution of Diabetic Maculopathy on } \\
Conventional Fundoscopy & \\
\hline
\end{tabular}

\begin{tabular}{|ccc|}
\hline ETDRS Maculopathy Fundus Imaging & Frequency & Percent \\
No Maculopathy & 55 & 91.667 \\
CSME & 5 & 8.333 \\
\hline \multicolumn{3}{|c|}{ Table 6. Frequency Distribution of Diabetic Maculopathy } \\
on Fundus Imaging. \\
\hline
\end{tabular}

In our study, absence of maculopathy was seen in 47 $(78.33 \%)$ of cases. The commonest maculopathy seen was diffuse macular oedema in 6 cases $(10 \%)$.
Since imaging has the constraint of 2 dimension photograph, not all types of maculopathy could be confirmed except no maculopathy and CSME, with the frequency of no maculopathy being 55 (91\%).

\begin{tabular}{|cccccc|}
\hline \multicolumn{5}{c|}{$\begin{array}{c}\text { ETDRS Background } \\
\text { Retinopathy Fundus Imaging }\end{array}$} \\
$\begin{array}{c}\text { ETDRS Background Retinopathy } \\
\text { Mild }\end{array}$ & $\begin{array}{c}\text { Moderate Severe } \\
\text { Conventional Fundoscopy }\end{array}$ & NPDR & NPDR & NPDR & PDR Total \\
Mild NPDR & 14 & 0 & 0 & 0 & 14 \\
Moderate NPDR & 0 & 25 & 0 & 0 & 25 \\
Severe NPDR & 0 & 0 & 11 & 0 & 11 \\
PDR & 0 & 0 & 0 & 10 & 10 \\
Total & $\mathbf{1 4}$ & $\mathbf{2 5}$ & $\mathbf{1 1}$ & $\mathbf{1 0}$ & $\mathbf{6 0}$ \\
\hline & $\mathrm{P}=<.001$ & & & & \\
\hline $\begin{array}{c}\text { Table 7. Contingency Table Comparing Conventional Fundoscopy with } \\
\text { Fundus Imaging on ETDRS Classification with Statistical Analysis }\end{array}$ \\
\hline
\end{tabular}

In Table 7, we found an association/agreement between the two modalities of fundus imaging with a $P$ value of $<.001$ on the chi-square test, indicating that both fundus imaging and conventional fundoscopy gave consistent results on background diabetic retinopathy.

\begin{tabular}{|cccc|}
\hline ETDRS Maculopathy Conventional & $\begin{array}{c}\text { ETDRS Maculopathy } \\
\text { Fundus Imaging }\end{array}$ \\
Ophthalmoscopy & No Maculopathy & CSME & Total \\
No Maculopathy & 47 & 0 & 47 \\
CSME & 0 & 5 & 5 \\
Ischemic maculopathy & 2 & 0 & 2 \\
Diffuse macular oedema & 6 & 0 & 6 \\
Total & 55 & 5 & 60 \\
\hline Table 8. Contingency Table Comparing Conventional Fundoscopy \\
for Maculopathy with Fundus Imaging for Maculopathy with \\
\multicolumn{3}{|c}{ Statistical Analysis } \\
\hline
\end{tabular}

In Table 8, it was found that there was a significant agreement between fundus imaging and conventional fundoscopy for the absence of maculopathy and clinically significant macular oedema on ETDRS, with a P-value of < 0.001 on the chi-square test.

However, ischemic maculopathy and diffuse macular oedema could not be picked up on fundus imaging but were classified only on conventional fundoscopy. No statistical agreement could be concluded on these two types of maculopathies.

\begin{tabular}{|cc|}
\hline & Kappa Coefficient ( $)$ \\
ETDRS background retinopathy conventional fundoscopy & 1.00 \\
VS ETDRS background retinopathy fundus imaging & \\
\hline $\begin{array}{c}\text { Table 9. Kappa Statistics Table Showing Agreement between } \\
\text { Conventional Funduscopy and Fundus Imaging for Background } \\
\text { Retinopathy }\end{array}$
\end{tabular}

In table 9 we see a perfect agreement between conventional funduscopy and retinal fundus imaging for background retinopathy.

\begin{tabular}{|cc|}
\hline $\begin{array}{c}\text { ETDRS maculopathy conventional ophthalmoscopy vs } \\
\text { ETDRS maculopathy fundus imaging }\end{array}$ & Kappa Coefficient (k) \\
\hline $\begin{array}{c}\text { Table 10. Kappa Statistics Table Showing Agreement between } \\
\text { Conventional Funduscopy and Fundus Imaging for Diabetic } \\
\text { Maculopathy }\end{array}$ \\
\hline
\end{tabular}

In table 10 we observed a moderate agreement between conventional funduscopy and fundus imaging for diabetic maculopathy, as mentioned above ischemic maculopathy and diffuse macular oedema could not be picked up on fundus imaging but were classified only on conventional fundoscopy. 


\section{DISCUSSION}

The study found the common age of presentation of diabetic retinopathy to be 56 to 65 years. A study by Mangala, Kusuma et al. showed that $50 \%$ of cases of type 2 diabetes mellitus were in $45-65$ years of age. ${ }^{14}$

Another study by Vijayalakshmi et al. showed the age of presentation as $53.5 \pm 12.9$ years. This also concurred with the study findings. ${ }^{15}$

This study also found a marginal male preponderance in diabetic retinopathy presentation with 35 (58.33\%) cases. Since it was a tertiary care hospital-based study, it was found that male members presented to the healthcare system more often compared to females.

In the study by Mangala et al., out of $84 \%$ of patients, 69 $\%$ were females and $31 \%$ were males. ${ }^{14}$ Another study from South India by Dhruv et al., at a diabetic care centre, showed a male preponderance of about $60 \%$ of patients presenting with type 2 diabetes mellitus. Their findings concurred with ours. ${ }^{16}$

The commonest type of retinopathy found on conventional fundoscopy was, moderate NPDR in 25 (41.667 $\%$ ) based on ETDRS classification. The same findings were also seen in imaging type of evaluation of background retinopathy with moderate NPDR seen in 25 (41.66\%) of cases. The findings were concurrent with that of ours.

In a study by Mulgundi et al., moderate NPDR was seen in $28 \%$ of their cases. In other studies, namely Bertram et al. and Ramseval et al. the presentation of mild and moderate cumulative retinopathies ranged from $19 \%$ to $21.4 \% .^{17,18}$

However, Sumi S et al. and Mulungdi et al. found cumulative mild and moderate NPDR in $71 \%$ and $70 \%$ respectively. ${ }^{19}$

On the evaluation of diabetic maculopathy on conventional funduscopy, the commonest maculopathy found was the absence of any changes in Macula in about 47(78.3 $\%$ ) of cases. Amongst the maculopathy cases, the commonest one was diffuse macular oedema, seen in $6(10 \%)$ of cases. Clinically significant macular oedema was seen in 5 cases $(8.33 \%)$ in conventional fundoscopy.

The disadvantage of fundus imaging is that it is a twodimensional image and hence certain types of diabetic maculopathies could not be concluded on it. Hence the absence of maculopathy was reported in 55 (91.667 \%) of the cases. The only other type of maculopathy that could be evaluated on fundus imaging was clinically significant macular oedema which was seen in 5 cases ( $8.33 \%)$

Table 7 is the contingency table wherein the chi-square test, which is a statistical test, was applied for agreement between conventional fundoscopy and fundus imaging.

The value was seen to be $<0.001$, and hence it can be concluded that even fundus imaging could positively conclude on the type of background diabetic retinopathy based on ETDRS classification. This agreement proves that fundus imaging used as a tool in telemedicine to combat diabetic retinopathy related visual impairment can be effective. Thus, manual evaluation by a trained ophthalmologist may not be required. These technologies will bridge the gap of lack of ophthalmologists in remote areas and help in screening and early detection of diabetic retinopathies.
In a study by Schulze et al., 5 years of experience in fundus imaging showed an effective screening tool for diabetic retinopathy. ${ }^{20}$

In another study by Owsley et al., they found $21.7 \%$ of uniocular diabetic retinopathy. The commonest type was background diabetic retinopathy seen in $94.1 \%$ of cases. ${ }^{21}$ Most of the diabetic screening programs use different types of fundus photography. While America and Canada used 7 field fundus imaging, 5 fields were used in France and Spain. ${ }^{22}$

In a German project ultra-widefield, one field picture was used for fundus evaluation. . $3,24^{2}$

However, irrespective of the type of fundus photography, fundus imaging was found to be an effective tool for diabetic retinopathy screening and helped in conditions of lack of retinal specialist. ${ }^{25}$

In table 8, contingency table statistical analysis was applied to the comparison of conventional fundoscopy with fundus imaging of the macula. The comparison was done only between the absence of maculopathy and the CSME type of maculopathy, and the agreement for these two types was considered for the two types of evaluation.

A statistically significant agreement was seen on applying the chi-square test with a P-value of $<0.001$. This proved that there was a concurrence between the two methods of evaluation for detection of clinically significant macular oedema and absence of maculopathy.

In table $9 \& 10$ on applying inter-rater reliability, Cohen's Kappa statistics ${ }^{26}$, we found a perfect agreement (k-1) between fundus imaging and conventional funduscopy for screening background retinopathy and a moderate agreement (k-0.51) for diabetic maculopathy screening in both the mentioned methods under ETDRS.

In a study conducted by Malerbi et al. who found an agreement between BIO (binocular indirect ophthalmoscopy) and mydriatic retinography that was substantial (kappa 0.670.74) for diabetic retinopathy observation vs. referral classification. The agreement was fair to moderate (kappa 0.24-0.45) between retinography and BIO for maculopathy. The difference in results in these two studies was that our study had a smaller sample size. ${ }^{27}$ The commonest cause of vision loss in type 2 diabetes mellitus was diabetic macular oedema. ${ }^{28}$ Non-stereoscopic fundus photography was used in ours and in most studies, which interferes with the correct assessment of diabetic maculopathy. Since only clinically significant macular oedema is detected on these photographs, only the more severe spectrum of DME gets evaluated. The prevalence of DME among patients with diabetes was generally much lower than that of DR, this was also seen in this study. ${ }^{29,30,31,32,33}$ In diabetic retinopathy screening services study, the prevalence of DME was found to be only $1.4 \%$ in type 2 diabetes mellitus. ${ }^{34}$ In two other studies, one from Kenya and another from Canada found diabetic macular oedema prevalence as $33 \%$ and $15.3 \%$ respectively, but their screening methodology was stereoscopic fundus evaluation by a trained ophthalmologist. ${ }^{35}$ Hence this brings to us the understanding that non-stereoscopic fundus photographs may be underdiagnosing DME.

Another diabetic maculopathy review in the Cochrane database largely over-diagnosed diabetic maculopathy using optical coherence tomography, giving a large range of prevalence extending from 19 to $65 \%$. OCT-detected DME 
disagreed with the clinical definition of CSME, and many patients of OCT detected macular thickening progressed to CSME.

In this study, we conclude that a non-stereoscopic fundus photograph was able to differentiate between the absence of maculopathy and clinically significant macular oedema. The statistical analysis showed significant results.

\section{CONCLUSIONS}

The study found a significant correspondence between conventional fundoscopy and non-stereoscopic fundus photography in terms of diagnosis of background retinopathy. Similar concurrence was not found in the diagnosis of diabetic maculopathies. Non-stereoscopic fundus photography showed a significant agreement with conventional fundoscopy in diagnosing clinically significant macular oedema and absence of maculopathy, nevertheless, diffuse macular oedema and ischemic macular oedema were under-diagnosed with fundus photography.

Non-stereoscopic fundus photography gave promising results as a telemedicine tool and evaluation of diabetic retinopathy in remote areas with a lack of ophthalmologists. But the interpretation of maculopathy through this tool must be done cautiously, being mindful of underdiagnosing maculopathies by the non-stereoscopic fundus photographs.

\section{Limitation of Study}

The study was conducted in a tertiary care centre; a community-based study and a larger sample size is desirable for better impact of the conclusion.

Data sharing statement provided by the authors is available with the full text of this article at jemds.com.

Financial or other competing interests: None.

Disclosure forms provided by the authors are available with the full text of this article at jemds.com.

\section{REFERENCES}

[1] Lee R, Wong TY, Sabanayagam C. Epidemiology of diabetic retinopathy, diabetic macular edema and related vision loss. Eye Vis (Lond) 2015;2:17.

[2] Bourne RRA, Stevens GA, White RA, et al. Causes of vision loss worldwide, 1990-2010: a systematic analysis. Lancet Glob Health 2013;1(6):e339-49.

[3] Das T, Raman R, Ramasamy $K$, et al. Telemedicine in diabetic retinopathy: current status and future directions. Middle East Afr J Ophthalmol 2015;22(2):174-8.

[4] Salz DA, Witkin AJ. Imaging in diabetic retinopathy. Diabetic Retinopathy Update 2015;22(2):145-50.

[5] Tennant MT, Greve MD, Rudnisky CJ, et al. Identification of diabetic retinopathy by stereoscopic digital imaging via teleophthalmology: a comparison to slide film. Can J Ophthalmol 2001;36(4):187-96.

[6] Liesenfeld B, Kohner E, Piehlmeier W, et al. A telemedical approach to the screening of diabetic retinopathy: Digital fundus photography. Diabetes Care 2000;23(3):345-8.
[7] Singh AK. Ophthalmic problems in remote areas of India. Indian J Ophthalmol 2018;66(7):975.

[8] Wilkinson CP, Ferris FL, Klein RE, et al. Proposed international clinical diabetic retinopathy and diabetic macular edema disease severity scales. Ophthalmology 2003;110(9):1677-82.

[9] Klein R, Knudtson MD, Lee KE, et al. The Wisconsin epidemiologic study of diabetic retinopathy: XXII the twenty-five-year progression of retinopathy in persons with type 1 diabetes. Ophthalmology 2008;115(11):1859-68.

[10] Grading diabetic retinopathy from stereoscopic color fundus photographs--an extension of the modified Airlie House classification. ETDRS report number 10. Early Treatment Diabetic Retinopathy Study Research Group. Ophthalmology 1991;98(5 Suppl):786-806.

[11] Bresnick GH. Diabetic macular edema. A review. Ophthalmology 1986;93(7):989-97.

[12] Agarwal D, Bansal A. Non-invasive techniques for the screening of diabetic retinopathy. J Biomed Imag Bioeng 2017;1(2):25-30.

[13] Rosas-Romero R, Martínez-Carballido J, HernándezCapistrán J, et al. A method to assist in the diagnosis of early diabetic retinopathy: image processing applied to detection of microaneurysms in fundus images. Comput Med Imaging Graph 2015;44:41-53.

[14] Borkar M, Sikariya K, Chonde GA, et al. Clinical profile of type 2 diabetes. World Journal of Pharmaceutical and Medical Research 2017;3(6):294-8.

[15] Vijayalakshmi UB, Bodi AV, Sudagani J. Biochemical and clinical profile in type 2 diabetics with depression. J Clin Diagn Res 2016;10(8):BC19-23.

[16] Nair DR, Satheesh K, Raghavan A, et al. Trend in the clinical profile of type 2 diabetes in India - study from a diabetes care centre in South India. Diabetes Metab Syndr 2020;14(6):1851-7.

[17] Bertram B. Prevalence of patients with diabetes mellitus without and with retinopathy is an ophthalmology practice. Ophthamologe 1997;94(6):401-4.

[18] Ramsevak V, Ling R, Tylord D, et al. Longitudinal study of a cohort of people with diabetes screened by the Exeter Diabetic Retinopathy Screening Programme. Eye (Lond) 2002;16(2):140-5.

[19] Mulgund U, Chandran R. assessment of diabetic retinopathy by fluorescein angiography. International Journal of Contemporary Medical Research 2017;4(10):2104-9.

[20] Schulze-Döbold C, Erginay A, Robert N, et al. Ophdiat $(\AA)$ : five-year experience of a telemedical screening programme for diabetic retinopathy in Paris and the surrounding area. Diabetes Metab 2012;38(5):450-7.

[21] Owsley C, McGwin G, Lee DJ, et al. Diabetes eye screening in urban settings serving minority populations: detection of diabetic retinopathy and other ocular findings using telemedicine. JAMA Ophthalmol 2015;133(2):174-81.

[22] Creuzot-Garcher C, Malvitte L, Sicard AC, et al. How to improve screening for diabetic retinopathy: the Burgundy experience. Diabetes Metab 2010;36(2):1149. 
[23] Kernt M, Hadi I, Pinter F, et al. Assessment of diabetic retinopathy using nonmydriatic ultra-widefield scanning laser ophthalmoscopy (Optomap) compared with ETDRS 7-field stereo photography. Diabetes Care 2012;35(12):2459-63.

[24] Liegl R, Liegl K, Ceklic L, et al. Nonmydriatic ultra-widefield scanning laser ophthalmoscopy (Optomap) versus two-field fundus photography in diabetic retinopathy. Ophthalmologica 2014;231(1):31-6.

[25] Pieczynski J, Gryzybowski A. Review of diabetic retinopathy screening methods and programmes adopted in different parts of the world. European Ophthalmic Review 2015;9(1):49-55.

[26] McHugh M. Interrater reliability: the kappa statistic. Biochem Med (Zagreb) 2012;22(3):276-82.

[27] Malerbi FK, Morales PH, Farah ME, et al. Comparison between binocular indirect ophthalmoscopy and digital retinography for diabetic retinopathy screening: the multicenter Brazilian Type 1 Diabetes Study. Diabetol Metab Syndr 2015;7:116.

[28] Lightman S, Towler HM. Diabetic retinopathy. Clin Cornerstone 2003;5(2):12-21.

[29] Bertelsen G, Peto T, Lindekleiv H, et al. Tromso eye study: prevalence and risk factors of diabetic retinopathy. Acta Ophthalmol. 2013;91(8):716-21.
[30] Kaidonis G, Mills RA, Landers J, et al. Review of the prevalence of diabetic retinopathy in Indigenous Australians. Clin Experiment Ophthalmol 2014;42(9):875-82.

[31] Virgili G, Menchini F, Murro V, et al. Optical coherence tomography (OCT) for detection of macular oedema in patients with diabetic retinopathy. Cochrane Database Syst Rev 2011;7:CD008081.

[32] Klein R, Knudtson MD, Lee KE, et al. The Wisconsin epidemiologic study of diabetic retinopathy XXIII: the twenty-five-year incidence of macular edema in persons with type 1 diabetes. Ophthalmology 2009;116(3):497503.

[33] Ding J, Wong TY. Current epidemiology of diabetic retinopathy and diabetic macular edema. Curr Diab Rep 2012;12(4):346-54.

[34] Thomas RL, Dunstan FD, Luzio SD, et al. Prevalence of diabetic retinopathy within a national diabetic retinopathy screening service. $\mathrm{Br} \mathrm{J}$ Ophthalmol 2015;99(1):64-8.

[35] Mathenge W, Bastawrous A, Peto T, et al. Prevalence and correlates of diabetic retinopathy in a population-based survey of older people in Nakuru, Kenya. Ophthalmic Epidemiol 2014;21(3):169-77. 